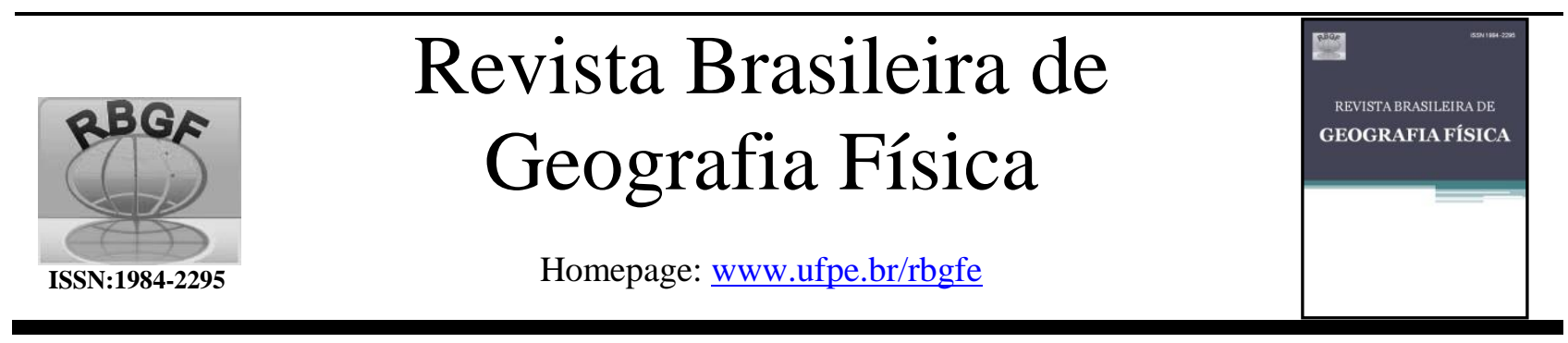

\title{
Os biomas e o clima das capitais do Brasil
}

\author{
Elenice Fritzsons ${ }^{1}$, Luiz Eduardo Mantovani ${ }^{2}$, Marcos Silveira Wrege ${ }^{3}$
}

${ }^{1}$ Dra. em Eng. Florestal, Embrapa Florestas, Colombo, PR, CEP 83411-000, km 111, Estrada da Ribeira, Colombo - PR, Telefone: (41) 3675-5698, autor correspondente: elenice.fritzsons @embrapa.br; ${ }^{2}$ Prof. do Depto de Geologia, UFPR, Curitiba, PR, Av. Cel. Francisco H. dos Santos, s/n - Jardim das Américas, Curitiba - PR, 81270-460, lem@ufpr.br; ${ }^{3}$ Dr. em Agronomia, Embrapa Florestas, Colombo, PR, CEP 83411-000, km 111, Estrada da Ribeira, Colombo - PR, Telefone: (41) 3675-5698, marcos.wrege@embrapa.br.

Artigo recebido em 04/05/2017 e aceito em 05/08/2017

\section{R E S U M O}

$\mathrm{O}$ clima tem forte influência sobre os tipos de vegetação e o Brasil apresenta diferentes tipos de clima e de biomas. $\mathrm{O}$ objetivo deste trabalho é comparar, com auxílio da análise estatística multivariada, os diferentes tipos de clima existentes nas capitais brasileiras, relacionando-os aos vários biomas. Foram obtidos os seguintes dados climáticos das capitais: temperatura média anual, média das máximas, média das mínimas, insolação média anual, evaporação média anual, umidade relativa anual, média do total pluviométrico anual e da disponibilidade hídrica. Os dados foram utilizados para formar grupos (análise de cluster) e, depois dos grupos formados, foi feita a análise de variância e identificadas as médias. Dois grandes grupos (A e B) e cinco subgrupos se formaram. No subgrupo A1, estão as capitais do sul do País e uma do sudeste, sendo que a Mata Atlântica predomina; no A12, capitais do sudeste e centro oeste e o Cerrado predomina. No subgrupo B11, na faixa litorânea do sudeste até o nordeste, predomina a Mata Atlântica e o subgrupo B12 pertence ao Bioma Amazônia. O bioma mais representado nas capitais brasileiras é a Mata Atlântica, com 10 capitais, seguido do Cerrado com 7 e a Amazônia, com 6. A Caatinga e o Pampa estão representados por uma capital cada e ainda há duas capitais em transição de bioma: Belo Horizonte e Natal. A maior presença de capitais no bioma Mata Atlântica deve-se ao processo de colonização, do litoral para o interior do país, o que justifica também a sua forte degradação.

Palavras-chave : Mata Atlântica, análise multivariada, temperatura, precipitação.

\section{The biomes and climate of Brazilian capitals}

\begin{abstract}
A B S T R A C T
The climate has a strong influence on vegetation types and Brazil presents different types of climate and biomes. The objective of this work is to compare, with the aid of multivariate statistical analysis, the Brazilian capitals regarding the climate and relate them to the biomes. The following climatic data were taken: annual mean temperature, maximum average, minimum average, annual mean isolation, annual average evaporation, annual relative humidity and mean annual rainfall and water availability. After the groups were formed, analysis of variance was performed and means were identified. Two large groups (A and B) and five subgroups were formed. The subgroup A1 is formed by the capitals of the south of the Country and one of the southeast and Atlantic Forest predominates, in the A12, capitals of the southeast and center west, where Savannah dominates. In the subgroup B11, the Atlantic Forest predominates, in the coastal strip from the southeast to the northeast and the subgroup B12 belongs to the Amazon Biome. The most represented biome is the Atlantic Forest, with 10 capitals, followed by the Savannah with 7 and the Amazon with 6. There is one in the Caatinga and another in the Pampa and there are still two capitals in transition from biome: Belo Horizonte and Natal. The predominant presence of Atlantic Forest Biome is due to the colonization process of Brazil, from the coast to the interior, which justifies the fact that it is the most degraded biome among them.
\end{abstract}

Keywords: Atlantic Forest, multivariate analysis, temperature, precipitation. 


\section{Introdução}

O Brasil é um país com dimensões continentais e apresenta diferentes tipos de clima, desde o semiárido tropical, com pluviosidade inferior a $600 \mathrm{~mm}$, até climas equatoriais, tropicais e subtropicais, com pluviosidade superior a 3300 $\mathrm{mm}$ (Ramos, 2009). Desde o clima quente superúmido no noroeste até o temperado úmido no sul e, de acordo com a classificação climática de Köppen-Geiger, há desde o clima tropical (Af, Am, Aw, As), o clima semiárido (Bsh) até o subtropical úmido (Cfa, Cfb, Cwa, Cwb, Cwc, Csa, Csb) (IBGE, 2004). A classificação climática de Köppen-Geiger é baseada no pressuposto de que a vegetação natural de cada grande região da Terra é uma expressão do clima nela prevalecente. Nessa classificação climática, foram considerados a sazonalidade e os valores médios anuais e mensais da temperatura do ar e da pluviosidade (Rolim et al., 2007).

O ambiente físico, especialmente a variação anual de temperatura e da pluviosidade, afeta a estrutura e as características das comunidades biológicas, influenciando diretamente na fauna e na flora de cada região (Primack e Rodrigues, 2001). De acordo com o IBGE (2004), temos diversos biomas (Amazônia, Cerrado, Caatinga, Mata Atlântica, Pantanal e

\section{Material e métodos}

Foram usados os seguintes dados climáticos nas capitais brasileiras: temperatura média anual, média da temperatura máxima, média da temperatura mínima, insolação média anual, evaporação média anual, umidade relativa anual, média do total pluvial anual e da disponibilidade hídrica (diferença entre a pluviosidade e a evapotranspiração) para todas as capitais. Os dados foram obtidos das Normais Climatológicas do Brasil (Ramos et al., 2009), compilados em planilhas eletrônicas e submetidos às análises

\section{Resultados e discussão}

Podemos separar as capitais em dois grandes grupos, observando $\mathrm{O}$ dendrograma formado pela análise de cluster (Figura 1): A e B. O grupo A representa as capitais do sul do país (A11), sendo composto por Curitiba, Florianópolis e Porto Alegre, São Paulo e capitais do sudeste e centro oeste (A12), Belo Horizonte, Brasília, Goiânia e Campo Grande.

$\mathrm{O}$ grupo $\mathrm{B}$ abrange maior número de capitais e se divide em dois subgrupos (B1 e B2).
Pampa) e neles ocorrem diversos tipos de vegetação e a relação entre capitais e biomas é a seguinte: Amazônia (Belém, Macapá, São Luis, Manaus, Porto Velho, Rio Branco); Mata Atlântica (Curitiba, Florianópolis, São Paulo, Aracaju, João Pessoa, Maceió, Salvador, Recife, Rio de Janeiro, Vitória); Cerrado (Campo Grande, Goiânia, Brasília, Cuiabá, Palmas, Teresina, Boa Vista); Pampa (Porto Alegre); Caatinga (Fortaleza); Transição Mata Atlântica - Cerrado (Belo Horizonte); Transição Mata atlântica - Caatinga (Natal).

As diferenças na vegetação e no clima implicam em diversas modalidades temáticas: no planejamento hídrico, saneamento básico, na saúde, no planejamento paisagístico e arquitetônico e prevenção contra enchentes, economia de energia, e até implicações no turismo, pois uma grande parte das capitais brasileiras são cidades turísticas.

O objetivo deste trabalho é comparar, por meio de análise estatística multivariada, o clima das capitais brasileiras, relacionando-as aos diferentes biomas nos quais ocorrem e, com isso, auxiliar na formulação de políticas públicas para o país.

estatísticas. Primeiramente, foi feita a análise de cluster, com o objetivo de reunir as capitais com os tipos de clima semelhantes. Depois de compostos os grupos, foi feita a análise de variância (ANOVA), para verificar diferenças significativas entre os grupos e foram identificadas médias diferentes. A visualização do teste foi feita com o Gráfico de Médias. Foi utilizado o mapa de biomas brasileiros do IBGE (2004) para localizar as capitais.

O Subgrupo B1, por sua vez, está subdividido em dois subgrupos B11 e B12. O B11 é composto por capitais situadas na costa litorânea do sudeste até o nordeste (Rio de Janeiro, Vitória, Aracajú, João Pessoa, Maceió, Salvador e Recife) e, no outro, B12, ocorrem duas capitais situadas na costa litorânea do nordeste (Fortaleza e Natal) e outras no interior do país (Cuiabá, Teresina e Boa Vista). No grupo B2, estão as capitais situadas no norte do 
país (Belém, Macapá, São Luis, Manaus, Porto

Velho e Rio Branco).

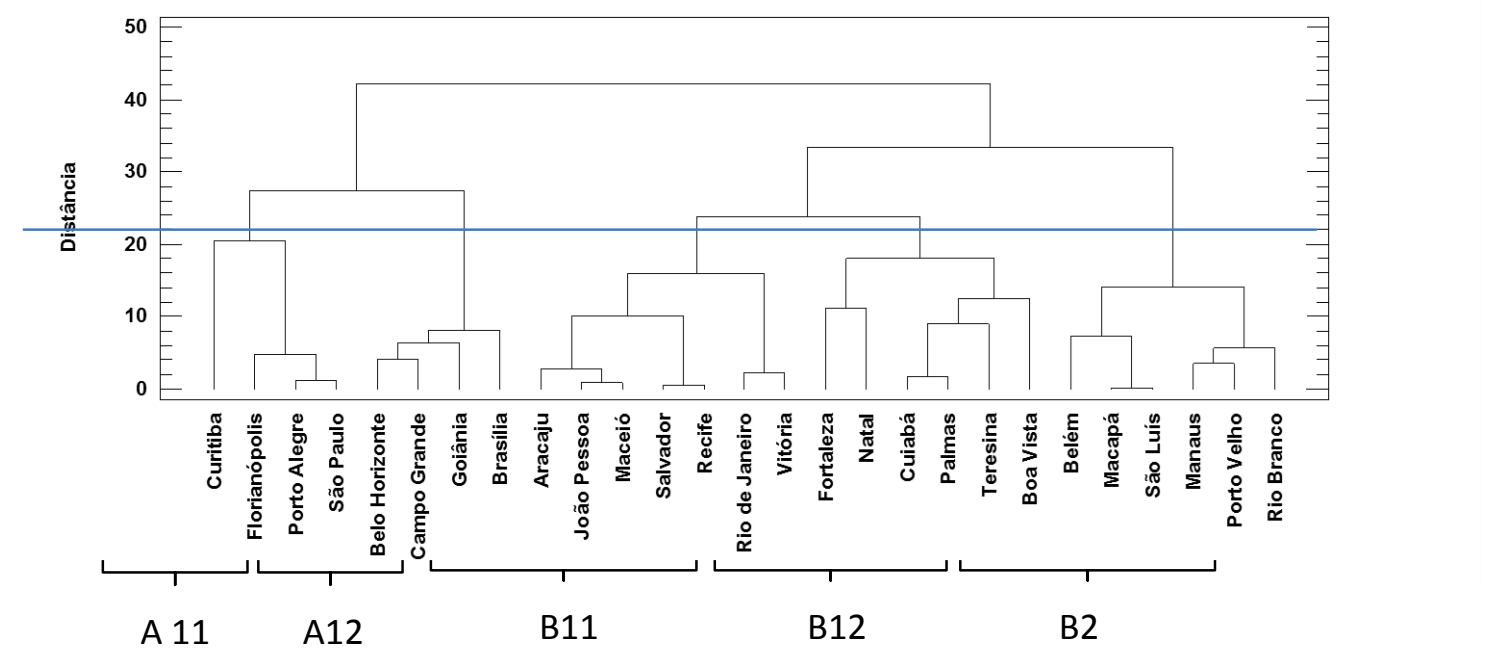

Figura 1. Dendrograma com os grupos formados pelas capitais brasileiras.

Como resultado da ANOVA, verificou-se que para todos os grupos e subgrupos ocorreram diferenças significativas para todas as variáveis climáticas (Tabela 2). Os valores médios, mínimos e máximos de cada variável, por grupo, podem ser observados na tabela 3 .

Tabela 2. Valores para a razão $\mathrm{F}$ e o valor $p$ para altitude, temperatura e precipitação para os 5 subgrupos das capitais brasileiras.

\begin{tabular}{lcc}
\hline Variáveis climáticas & Razão F & Valor P \\
\hline Temperatura média anual & 5,75 & $0,0025^{*}$ \\
Temperatura mínima média & 26,52 & $0,0000^{*}$ \\
Temperatura máxima média & 33,25 & $0,0000^{*}$ \\
Insolação & 4,85 & $0,0059^{*}$ \\
Evaporação & 7,33 & $0,0007^{*}$ \\
Umidade Relativa & 2,52 & $0,0000^{*}$ \\
Precipitação & 6,31 & $0,0015^{*}$ \\
Precipitação menos evaporação & 14,87 & $0.0000^{*}$ \\
\hline
\end{tabular}

* estatisticamente diferentes ao nível de $5 \%$ de probabilidade

Tabela 3. Valores médios, mínimos e máximos das variáveis climáticas para as capitais brasileiras.

\begin{tabular}{lccc}
\hline Variáveis climáticas & Média & Valor máximo & Valor mínimo \\
\hline Temperatura média anual $\left({ }^{\circ} \mathrm{C}\right)$ & 24,8 & 26,9 & 21,9 \\
Média da temperatura mínima anual $\left({ }^{\circ} \mathrm{C}\right)$ & 20,3 & 22,1 & 15,2 \\
Média da temperatura máxima anual $\left({ }^{\circ} \mathrm{C}\right)$ & 29,2 & 31,7 & 24,2 \\
Insolação média anual (horas) & 2361 & 2541 & 2068 \\
Evapotranspiração média anual $(\mathrm{mm})$ & 1196 & 1568 & 987 \\
Umidade Relativa média anual $(\%)$ & 77,7 & 84,6 & 69,6 \\
Média do total pluviométrico anual (mm) & 1742 & 2305 & 1440 \\
Precipitação menos evapotranspiração potencial média anual & 546 & 1478 & $-51,83$ \\
$(\mathrm{~mm})$ & & & \\
\hline
\end{tabular}

Quanto à temperatura média anual e média da mínima anual, o comportamento dos subgrupos foi semelhante. Os subgrupos A1 e A12 se separaram dos subgrupos B11, B12 e B2 (Figuras 2 e 3). Para a temperatura média máxima (Figura
4), o A1 apresentou as menores médias e foram formados mais 2 agrupamentos, sendo que o A12 é semelhante ao B11 e o B12 é semelhante ao B2. Assim, as temperaturas médias máximas mais elevadas estão no subgrupo da Amazônia e no

Fritzsons, E.; Mantovani, L. E., Wrege, M. S. 
grupo que envolve as capitais: Fortaleza, Natal, Palmas, Teresina e Boa Vista.

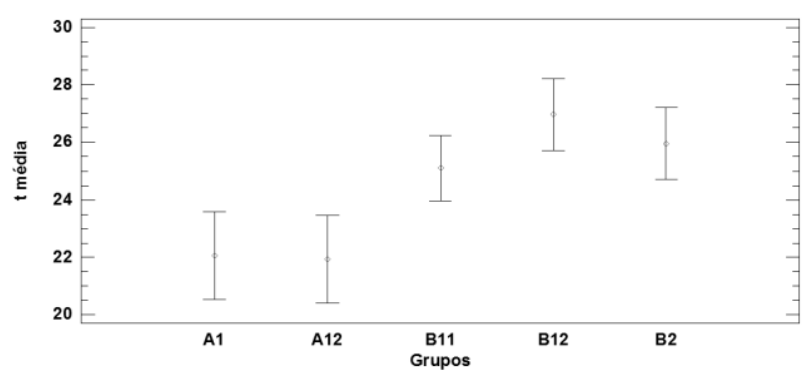

Figura 2. Gráfico de médias para temperatura média anual para os grupos das capitais.

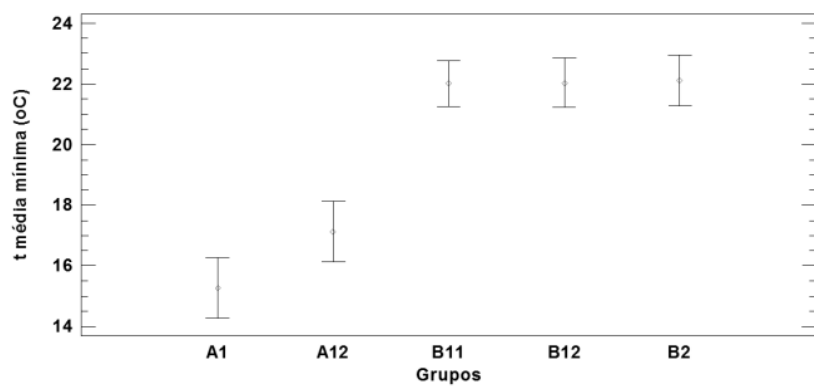

Figura 3. Gráfico de médias para temperatura média mínima anual para os grupos das capitais.

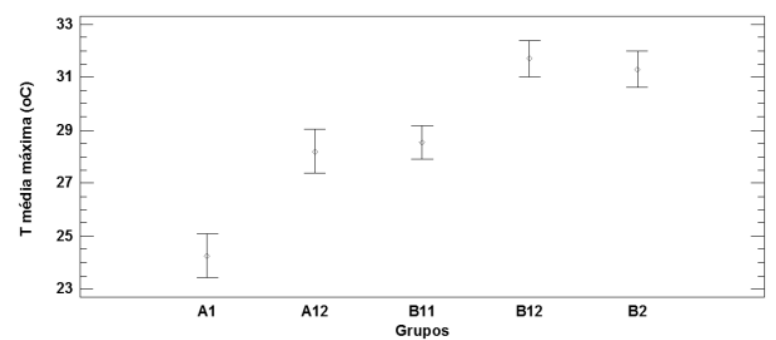

Figura 4. Gráfico de médias para temperatura média máxima para os grupos das capitais.

A evapotranspiração potencial mais elevada foi encontrada no grupo A12 (grupo de capitais do cerrado) e semelhante ao B12 (capitais situadas na orla do nordeste e no interior do país) e as mais baixas nos grupo A1 (capitais do sul) e, especialmente, B2, o qual apresenta a maior evapotranspiração (capitais do Bioma Amazônia) (Figura 5). 


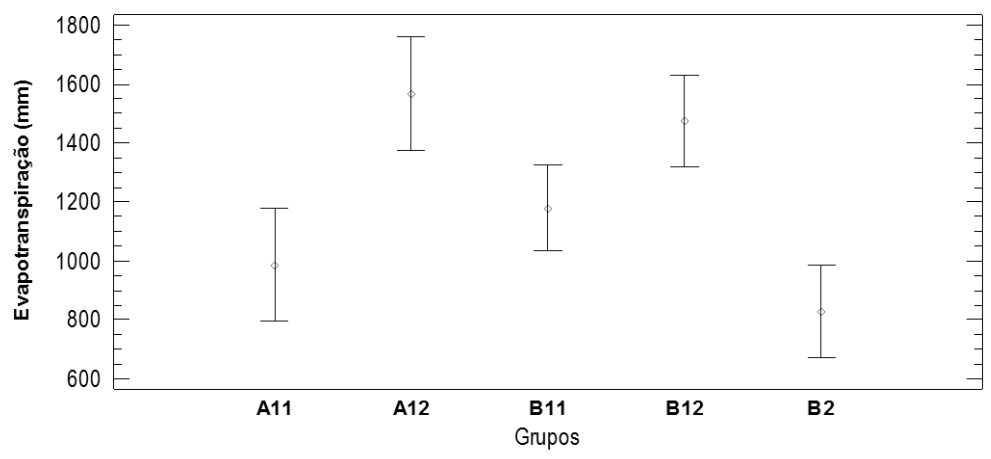

Figura 5. Gráfico de médias para evapotranspiração média anual para os grupos das capitais.

Para a umidade relativa, o comportamento é o oposto da evapotranspiração potencial, ou seja, quanto maior a evapotranspiração, menor a umidade relativa e vice-versa. Apenas no grupo B11 (grupo que pertence ao litoral sudeste/nordeste), esta tendência não ocorre, pois a evapotranspiração e umidade relativa apresentam valores intermediários, comparados aos outros subgrupos (Figura 6).

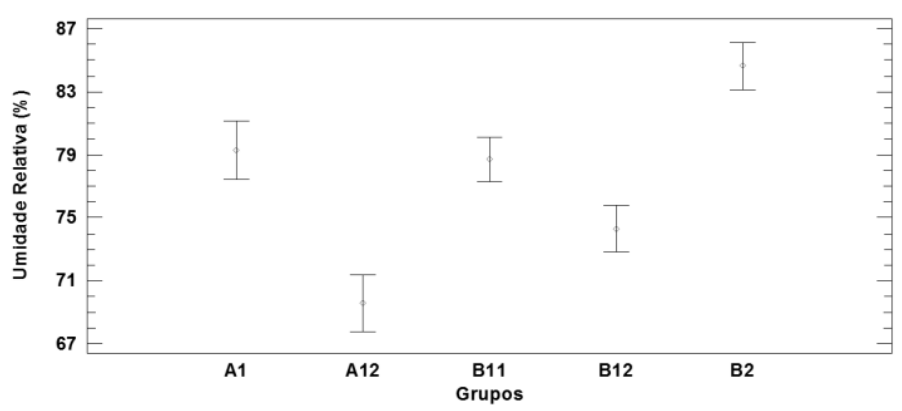

Figura 6. Gráfico de médias para umidade relativa anual para os grupos das capitais.

Quanto à insolação, é mais elevada nos grupos A12, B11 e B12, os quais não diferem entre si, mas diferem dos grupos A1 e B2, que apresentam médias semelhantes e mais baixas. Desta forma, as capitais do sul (A1) se assemelham as capitais do norte do país, na região norte amazônica, (B2) em termos de número de horas de sol (Figura 7). A igualdade em horas de insolação ocorre em termos de insolação efetiva, pois o período de brilho solar é maior nas Capitais do grupo B2. Quanto mais se afasta da Linha do Equador, menor o número de horas efetivo, mas esta compensação que resulta numa igualdade ocorre devido a grande cobertura de nuvens sobre a região Amazônica em grande parte do ano.

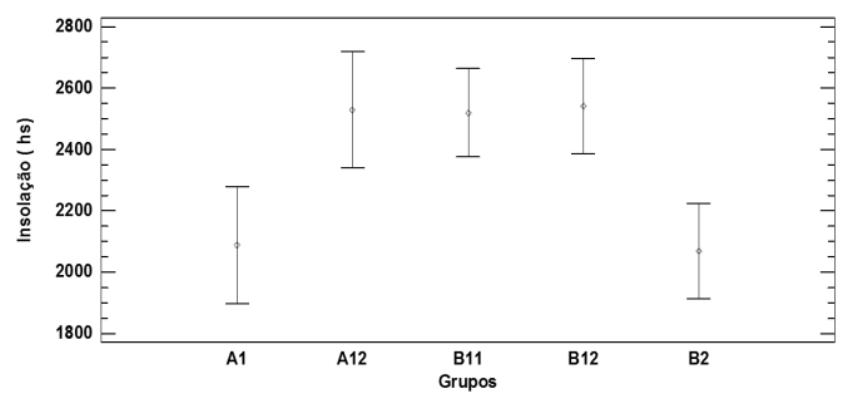

Figura 7. Gráfico de médias para insolação média anual para os grupos das capitais. 
Para a precipitação, o grupo B2 (Região Norte Amazônica) se destaca de todos os outros com precipitações bem mais elevadas (média de $2300 \mathrm{~mm}$ ). O subgrupo B11, das capitais do litoral do nordeste difere do subgrupo B12 (Fortaleza, Natal e outras capitais da zona central do país) pois a precipitação média das capitais do litoral é maior (Figura 8).

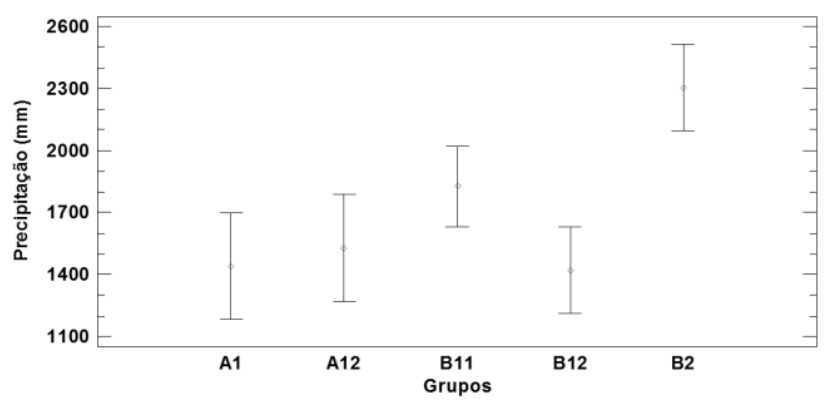

Figura 8. Gráfico de médias para precipitação para os grupos das capitais.

Quanto à disponibilidade hídrica, o subgrupo B2 difere dos outros subgrupos com o maior excedente dentre todas as capitais. Os menores excedentes ocorrem nos grupos A12 (Belo
Horizonte, Brasília, Goiânia e Campo Grande) e B12 (Fortaleza, Natal, Cuiabá, Teresina e Boa Vista) (Figura 9).

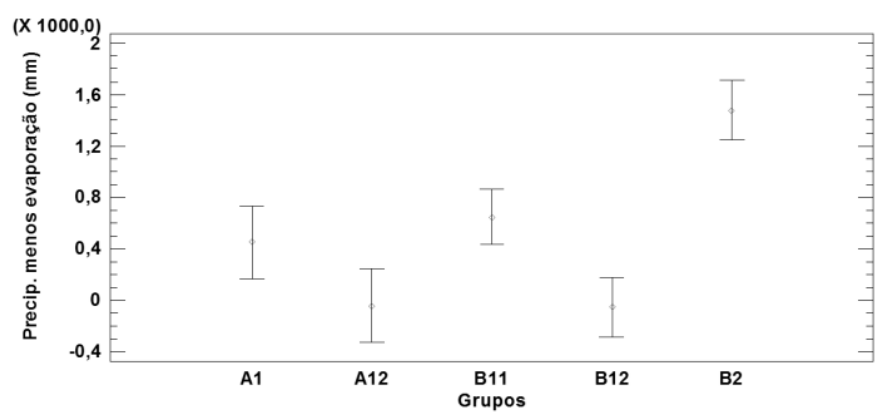

Figura 9. Gráfico de médias para disponibilidade hídrica para os grupos das capitais.

Assim, com a Análise de Cluster pode-se observar a separação de dois grandes grupos, A e B. No subgrupo A1 estão as capitais do sul do País (Curitiba, Florianópolis e Porto Alegre) e uma do sudeste (São Paulo). Desta forma, estas capitais estão todas situadas ao sul do Trópico de Capricórnio, que é uma linha divisória imaginária, muito importante em termos de alterações climáticas (Wrege et al., 2011). Observa-se que Curitiba, capital do Paraná (Figura 1), isola-se das demais capitais e que, Porto Alegre e São Paulo, apresentam-se com clima muito semelhante em relação aos parâmetros aqui considerados. São Paulo situa-se a $760 \mathrm{~m}$ de altitude e na latitude de $23,5^{\circ} \mathrm{S}$, alguns quilômetros ao sul do Trópico de Capricórnio, enquanto que a maior parte da zona urbana de Porto Alegre situa-se pouco acima do nível do mar, em altitude próximas de $10 \mathrm{~m}$ e na latitude de $30^{\circ} \mathrm{S}$. Desta forma, ocorre uma compensação da altitude com a latitude, e ambas as capitais, em termos médios, são climaticamente muito próximas no âmbito do presente estudo.

Apesar da semelhança climática, onde a pluviosidade de Porto Alegre é muito semelhante à de São Paulo, 1320 e 1440 mm, respectivamente, o tipo de vegetação de São Paulo é bastante diferente à de Porto Alegre, pois a primeira pertence o Bioma Mata Atlântica (Floresta Ombrófila Densa) (Kronka, 2005) e, a segunda, ao bioma Pampa, onde predominam campos, entremeados por capões de mata, matas ciliares e banhados. Isto ocorre porque a vegetação é bastante sensível ao clima, e neste trabalho, foram utilizadas as temperaturas médias e, não as absolutas. Porto Alegre atinge temperaturas muito mais baixas no inverno, com ocorrência de geadas, e temperaturas bem maiores no verão.

Por outro lado, Porto Alegre está sujeita a entradas de ar continental seco do setor oeste, com fases de vento aliado à baixa umidade do ar. Isto facilita a propagação de fogo e induz queimadas na 
vegetação, responsável pela formação dos campos pampianos, a exemplo do que ocorre no bioma Cerrado, situado no Brasil central e também em partes da Amazônia (Lehmann et al., 2014). No caso de São Paulo, é sensível o gradiente de temperaturas médias, que aumentam no sentido da periferia para a área central da megalópole sob efeito da ilha de calor urbano. Foi verificado que nos ambientes com ausência de vegetação, principalmente nos espaços ocupados por atividades da indústria, do comércio e de serviços, apresentam forte intensidade do fenômeno, com diferenças de temperaturas entre as regiões superiores a $8^{\circ} \mathrm{C}$ (Barros e Lombardo, 2016)

Curitiba se isola das demais capitais do subgrupo, pois é a capital mais fria do país e onde ocorre a formação vegetacional típica das regiões mais frias e úmidas, a Floresta Ombrófila Mista, conhecida também como Floresta com Araucária, tipo de vegetação que faz parte do bioma Mata Atlântica. Florianópolis, por sua vez, capital também presente no bioma Mata Atlântica, está sujeita a ingressos de ar frio com algumas ocorrências de geadas, porém não na intensidade suficiente para impedir o desenvolvimento de mangues no entorno da ilha de Santa Catarina.

Em geral, o subgrupo A1, formado pelas capitais do sul do país e São Paulo, caracteriza-se por apresentar as mais baixas temperaturas (média das médias, média das mínimas e média das máximas). A insolação é baixa e semelhante à do grupo B2, onde estão reunidas as capitais da região amazônica, como Belém, Macapá, São Luís, Manaus, Porto Velho e Rio Branco, devido à alta nebulosidade que ocorre em ambas as regiões (Wrege et al., 2011). Na meteorologia, a insolação representa o número de horas nas quais, durante o dia, o disco solar é visível para um observador situado à superfície terrestre, em um local com horizonte desobstruído. A insolação é, pois, o intervalo total de tempo, entre o nascimento e o pôr do sol, em que o disco solar não esteve oculto por nuvens ou fenômenos atmosféricos de qualquer natureza (Varejão-Silva, 2001). Insolação é um importante elemento meteorológico na Agricultura, pois está relacionado com a disponibilidade de radiação solar incidente, sendo um elemento que tem forte correlação com a produtividade vegetal e, além disso, é uma variável de entrada para modelos de estimativa da radiação solar (Estefanel et al., 1990)

No subgrupo A11, a umidade relativa é intermediária (entre 77 e 82\%) e, aliada a temperaturas médias mais baixas, têm como consequência uma evapotranspiração potencial relativamente baixa $(800$ a $1200 \mathrm{~mm})$. A pluviosidade é uma das menores entre os grupos (de 1320 a $1518 \mathrm{~mm}$ ) e, quanto à disponibilidade hídrica, situa-se em posição intermediária em relação aos demais subgrupos.

Ainda dentro do grupo A, temos o subgrupo A12, o qual reúne as capitais de Belo Horizonte, Campo Grande, Goiânia e Brasília, onde predomina o bioma Cerrado. Observa-se que as temperaturas médias dos grupos A11 e A12 são semelhantes e que a média das temperaturas mínimas, apesar de mais elevada no subgrupo A12, comparado ao subgrupo A11, não diferem significativamente, embora a média das temperaturas máximas seja maior no subgrupo A12. A insolação está entre as maiores entre os subgrupos e semelhantes aos subgrupos B11 e B12, como se pode comprovar no Atlas Solarimétrico do Brasil (Tiba, 2000). A pluviosidade assemelha-se ao subgrupo A1, B11 e B12 e a disponibilidade hídrica está entre as mais baixas, muito semelhante ao subgrupo B12, que é predominante no bioma Cerrado.

Quanto ao grupo B, o B11, com as capitais Aracajú, João Pessoa, Maceió, Salvador, Recife, Rio de Janeiro e Vitória, é o das capitais da região costeira do país, desde o sudeste até o nordeste. Este subgrupo apresenta as capitais com altas temperaturas médias e máximas e média das temperaturas mínimas com valores intermediários. A insolação é alta, mas a umidade relativa e a evapotranspiração são intermediárias, bem como os volumes totais da pluviosidade e a disponibilidade hídrica. Um destaque marcante neste grupo para as capitais nordestinas é a reduzida incidência de raios ou descargas elétricas, o que pode ser atribuído ao fato das ocorrências de chuvas serem devidas, em grande parte, às nuvens cúmulos quentes (Kraus e Businger, 1994) associados ao regime de alísios oceânicos, devido à proximidade com o oceano. Todas as capitais do subgrupo B11 situam-se no bioma Mata Atlântica.

O subgrupo B12, formado pelas capitais Fortaleza, Natal, Cuiabá, Teresina, Palmas e Boa Vista, é o mais disperso geograficamente entre os subgrupos, abrangendo uma diversidade de biomas. Há duas capitais do litoral norte do nordeste (Fortaleza e Natal), uma capital ao norte do Equador (Boa Vista), uma centro norte (Palmas) e uma no nordeste (Teresina). Cuiabá, Palmas e Teresina ocorrem no Cerrado (e Caatinga); Natal ocorre entre a transição da Caatinga e da Mata Atlântica; Fortaleza, na Caatinga (IBGE, 2004) e, Boa Vista, na região amazônica, mas em um clima equatorial. Neste subgrupo, as temperaturas, número de horas de sol e evapotranspiração estão entre as mais elevadas dentre os subgrupos. A 
umidade relativa é baixa e a disponibilidade hídrica é semelhante ao grupo A12 (Belo Horizonte, Campo Grande, Goiânia e Brasília). Este subgrupo poderia ser dividido ou reagrupado em outros grupos, se existissem informações climáticas mais detalhadas.

Natal e Fortaleza, apesar de serem capitais situadas na região litorânea, estão no bioma Caatinga e transição da Caatinga para a Mata atlântica e se separaram do subgrupo das capitais litorâneas do Brasil (subgrupo B11), onde predomina o bioma Mata Atlântica. Essas capitais também se apresentam com comportamento diferenciado em relação à insolação, o que pode ser verificado no Atlas Solarimétrico do Brasil (Tiba, 2000).

No grupo B2, formado pelas capitais: Belém, Macapá, São Luís, Manaus, Porto Velho e Rio Branco. Este grupo se isola dos demais e apresenta as maiores disponibilidade hídrica, pluviosidade e umidade entre os grupos. É um grupo homogêneo em termos de localização e clima, pois todas estão no bioma Amazônia e sob clima equatorial úmido. As temperaturas são elevadas e semelhantes ao grupo B12, porém a insolação e a evapotranspiração são baixas, favorecendo a ocorrência de maior umidade relativa do ar, com valores superiores a $83 \%$, na média anual. Quanto à temperatura média, o subgrupo é semelhante ao B12 e B11. Macapá situa-se na linha do Equador.

\section{Conclusões}

1. As dimensões continentais do Brasil resultam numa ampla variabilidade climática e de biomas a que pertencem as capitais brasileiras. O Bioma Mata Atlântica é o bioma mais representado pelas capitais embora os biomas Amazônia e Cerrado ocupem extensões territoriais maiores que o da Mata Atlântica.

2. A maior representação do Bioma Mata atlântica se dá devido à colonização brasileira, que se iniciou na costa brasileira em direção ao interior. Assim, as cidades mais antigas situamse no litoral, desde o sul até o norte do país. Esse processo se deu para a defesa da costa brasileira, onde está a maioria das capitais.

3. Outras variáveis climáticas poderiam ser utilizadas para separar melhor os subgrupos, tais como amplitude térmica, média das temperaturas mínimas absolutas e máximas absolutas.

4. Estudos como este podem ser bastante úteis para o planejamento das capitais brasileiras, considerando o turismo, a defesa civil, o planejamento arquitetônico e paisagístico, planejamento hídrico e energético (opções de utilização de fontes alternativas de energia) e, mesmo, monitoramento e prevenção de doenças associadas ao clima.

\section{Referências}

Barros, H. R.; Lombardo, M. A. 2016. A ilha de calor urbana e o uso e cobertura do solo no município de São Paulo-SP. GEOUSP: Espaço e Tempo (Online), 20. Disponível: http://dx.doi.org/10.11606/issn.2179-

0892.geousp.2016.97783. Acesso em: 25 abr. 2017.

Estefanel, V.; Schneider, F.M.; Berlato, M.A.; Buriol, G.A.; Heldwein, A. B. 1990. Insolação e radiação solar na região de Santa Maria, RS: I-Estimativa da radiação solar global incidente a partir dos dados de insolação. Revista do Centro de Ciências Rurais 20, 203-218.

IBGE Instituto Brasileiro de Geografia Física. 2004. Mapa de Biomas do Brasil, primeira aproximação. Rio de Janeiro: IBGE.

Kraus, E. B.; Businger, J. A. 1994. AtmosphereOcean Interaction. Oxford University Press, Cambridge, 362p.

Kronka, F. J. N. (coord). 2005. Inventário florestal da vegetação natural do estado de São Paulo. São Paulo: Governo do estado de São Paulo Secretaria do Meio Ambiente/Instituto Florestal. $200 \mathrm{p}$.

Lehmann, C. E. R., T. Michael Anderson, Mahesh Sankaran, Steven I. Higgins, Sally Archibald, William A. Hoffmann, Niall P. Hanan, Richard J. Williams, Roderick J. Fensham, Jeanine Felfili, Lindsay B. Hutley, Jayashree Ratnam, Jose San Jose, Ruben Montes, Don Franklin, Jeremy Russell-Smith, Casey M. Ryan, Giselda Durigan, Pierre Hiernaux, Ricardo Haidar, David M. J. S. Bowman, William J. Bond. 2014. Savanna Vegetation-Fire-Climate Relationships Differ Among Continents. Science Vol. 343, Disponível em: DOI: 10.1126/science. 1247355

Primack, R. B.; Rodrigues, E. 2001. Biologia da Conservação, Londrina, PR, 328 p.

Ramos, A. M.; Santos, L. A. R. dos; Fortes, L. T. G. (Org.). 2009. Normais climatológicas do Brasil 1961-1990. Rev. e ampl. Brasília, DF: INMET, 465 p. i

Rolim, Glauco de Souza; Camargo, Marcelo Bento Paes de; Lania, Daniel Grosseli; Moraes, Jener Fernando Leite de. 2007. Classificação climática de Köppen e de Thornthwaite e sua aplicabilidade na determinação de zonas agroclimáticas para o estado de são Paulo. Bragantia [online]. Disponível em: 
http://dx.doi.org/10.1590/S0006-

87052007000400022.

Tiba, Ch. (coord.). 2000. Atlas Solarimétrico do Brasil: banco de dados terrestres. Ed. Universitária da UFPE, Recife. 111 pp.

Varejão-Silva, M. A. 2001. Meteorologia e Climatologia. Brasília: INMET, Gráfica e Editora Pax, $532 \mathrm{p}$
Wrege, M. S.; Steinmetz, S.; Reisser Junior, C.; Almeida, I. R. de. (Ed.). 2011. Atlas climático da Região Sul do Brasil: Estados do Paraná, Santa Catarina e Rio Grande do Sul. Pelotas: Embrapa Clima Temperado. Colombo: Embrapa Florestas. 333 p. 